\title{
Detección oportuna del niño con trastorno del lenguaje
}

\section{Early detection of the child with language disorder}

Esther Lombardo-Aburto

\section{ANTECEDENTES}

Existen diferentes formas de comunicación por las que se transmite y recibe el mensaje mediante un código común y una vía o canal. Éstas pueden ser por medio de gestos, expresiones faciales, corporales, táctiles, sonoras, etc. ${ }^{1}$ sin embargo, son el lenguaje oral y escrito las que constituyen el grado más alto de la evolución lingüística priopio del ser humano. ${ }^{2}$

El lenguaje se define como un sistema de símbolos aprendidos que contienen un significado social que incluye las habilidades receptivas y expresivas. Las primeras reflejan la capacidad para entender el lenguaje y las segundas son la capacidad de pensamiento para expresar ideas y deseos hacia otros. ${ }^{3}$ El habla es la expresión oral del lenguaje, la producción y percepción de los símbolos para la comunicación de ideas, pensamientos, sentimientos y emociones; es la realización individual de una lengua o idioma.

El lenguaje es el sistema que regula todas nuestras conductas y emociones, y le da organización al pensamiento. ${ }^{4}$ Es el principal indicador del potencial de inteligencia.

El trastorno en el desarrollo del lenguaje es una de las manifestaciones más frecuentes en la consulta pediátrica, y es un reto para el pediatra porque no siempre se consigue que el niño hable durante la consulta. El pediatra debe valerse de herramientas para lograr que su paciente se comunique para evaluar el lenguaje que permita la detección temprana de algún trastorno y establecer estrategias favorables para evitar que trascienda a mayor edad. ${ }^{2}$
Consulta Externa de Pediatría, Instituto Nacional de Pediatría, Ciudad de México.

Recibido: 2 de marzo 2020

Aceptado: 3 de septiembre 2020

Correspondencia

Esther Lombardo-Aburto elombardoaburto@yahoo.com.mx

Este artículo debe citarse como Lombardo-Aburto E. Detección oportuna del niño con trastorno del lenguaje. Acta Pediatr Méx 2020; 41(5): 231-34. 


\section{Motivos de consulta}

Los padres acuden por diferentes motivos: porque su hijo no habla, porque habla mal, porque dejó de hablar o porque habla poco. Sin embargo, en muchas ocasiones, los padres consideran que su hijo tiene un lenguaje adecuado para su edad y es el pediatra quien detecta que es ininteligible, que hay algún retraso o cierto trastorno específico.

Qué debe conocer el pediatria para poder intervenir oportunamente:

1. El desarrollo normal del lenguaje y sus subcomponentes.

2. Las habilidades necesarias para el desarrollo verbal.

3. La importancia de la detección oportuna y de la intervención temprana.

El conocimiento adecuado del lenguaje forma parte del desarrollo psicomotor del niño que, muchas veces, no es explorado por el pediatra. Los trastornos del lenguaje son más frecuentes que las alteraciones en otras áreas del desarrollo y los padres y el pediatra los desconocen.

El desarrollo del lenguaje tiene una cronología que se expone en los Cuadros 1, 2 y 3

Cuadro 1. Prelingüística (0 a 1 a 6 meses)

\begin{tabular}{|l|l|}
\hline Edad & \multicolumn{1}{c|}{ Habilidades } \\
\hline 0 a 3 meses & $\begin{array}{l}\text { Comunicación a través de gestos, } \\
\text { sonidos guturales, bostezos, suspiros, } \\
\text { gritos, llanto, sonrisa social }\end{array}$ \\
\hline Ba a 5 meses & $\begin{array}{l}\text { Balbuceo con mayor frecuencia de } \\
\text { voz, sonidos graves }\end{array}$ \\
\hline 7 a 10 meses & $\begin{array}{l}\text { Sílabas consonante-vocal (mamama, } \\
\text { papapa) }\end{array}$ \\
\hline 9 a 18 meses & $\begin{array}{l}\text { Comprensión del lenguaje sencillo } \\
\text { Intensión comunicativa }\end{array}$ \\
\hline
\end{tabular}

Cuadro 2. Etapa de una palabra (1 a 2 años)

\begin{tabular}{|l|l|}
\hline Edad & Habilidades \\
\hline 1 a 2 años & $\begin{array}{l}\text { Emisión de palabras Emisiones de mono } \\
\text { y bisilábicas } \\
\text { Articulación correcta de todas las vocales }\end{array}$ \\
\hline 15 meses & 5 palabras mínimo \\
\hline 18 meses & 8 palabras mínimo \\
\hline 24 meses & Nombra imágenes en dibujo o señala \\
\hline
\end{tabular}

Cuadro 3.

\begin{tabular}{|c|c|c|}
\hline Etapa & Edad & Habilidades \\
\hline $\begin{array}{l}\text { Lenguaje } \\
\text { telegráfico }\end{array}$ & $\begin{array}{l}1^{\mathrm{a}} 6 \mathrm{~m} \\
-2 \text { a } 6 \\
\text { meses }\end{array}$ & $\begin{array}{l}\text { Emisiones de } 2 \text { o más palabras, con } \\
\text { frases: sustantivo-verbo } \\
\text { Jerga (habla en garabato) }\end{array}$ \\
\hline $\begin{array}{l}\text { Frases y } \\
\text { oraciones } \\
\text { simples }\end{array}$ & $\begin{array}{l}2 \text { años } \\
-3 \text { a } 6 \\
\text { meses }\end{array}$ & $\begin{array}{l}\text { Orden sustantivo-verbo-adjetivo } \\
\text { Capacidad para iniciar, seguir, } \\
\text { mantener y cambiar un tema }\end{array}$ \\
\hline $\begin{array}{l}\text { Oraciones } \\
\text { complejas }\end{array}$ & $\begin{array}{l}3 \text { a } 4 \\
\text { años }\end{array}$ & $\begin{array}{l}\text { Pronunciación Vacabulario en } \\
\text { expansión, gramática completa }\end{array}$ \\
\hline $\begin{array}{l}\text { Desarrollo } \\
\text { completo } \\
\text { del } \\
\text { enguaje }\end{array}$ & $\begin{array}{l}4 \text { a } 6 \\
\text { años }\end{array}$ & $\begin{array}{l}\text { Desarrollo de las funciones prag- } \\
\text { mática, vocabulario en expansión } \\
\text { y gramática completa }\end{array}$ \\
\hline
\end{tabular}

Para que se establezca el desarrollo adecuado del lenguaje es imprescindible que la audición sea adecuada y haya coordinación fonoarticulatoria, y habilidades cognitivas e intelectuales.

Existen diferentes hipótesis acerca de la adquisición del lenguaje oral:

4. Integridad de la función auditiva porque si no hay audición no hay lenguaje oral. El niño aprende a hablar por imitación, copiando los sonidos que se escuchan en su entorno.

5. Desde las 28 semanas de gestación el feto recibe sonidos porque la cóclea ya se ha formado. ${ }^{5}$

6. El lenguaje es una capacidad innata. La herencia juega un papel muy importante en la adquisición del lenguaje. 
7. El papel que juegan los padres, en especial la madre, en el desarrollo del lenguaje es por demás importante.

8. El ambiente y su entorno social, así como las clases sociales son un factor decisivo para el desarrollo del lenguaje.

Los trastornos del lenguaje pueden detectarse tempranamente (desde la etapa prelingüística), por lo que es necesario que el pediatra conozca el desarrollo del lenguaje.

- A los 5- 6 meses: ausencia de balbuceo

- A los 10 meses: ausencia o pobreza del balbuceo

- A los 18 meses: emisión de menos de 10 palabras o ninguna palabra inteligible (además de papá o mamá)

- A los 22 meses: ninguna expresión verbal, gestual o corporal

- A los 24 meses: ausencia de enunciados con dos palabras

- A los 30 meses: ausencia de enunciados con dos palabras, siendo una el verbo

- A los 36 meses: ausencia de enunciados con tres palabras (sujeto-verbo-objeto).

La detección temprana del trastorno del lenguaje es importante porque existen "ventanas de oportunidad" que son periodos en que es posible adquirir ciertas habilidades o destrezas de manera natural, sencilla y perdurable. Si no se detecta oportunamente, el niño no podrá aprenderla de manera apropiada.

Es muy importante conocer que la comprensión antecede a la expresión.

Abordaje inicial en el niño que se comunica mal

Es necesario determinar tres aspectos importantes para iniciar el abordaje:
1. Si hay un trastorno del habla o del lenguaje y valorar la función auditiva.

2. Si existe alguna alteración en los órganos fonoarticulatorios.

3. Si padece trastornos psicolingüísticos.

1. Trastornos del habla o lenguaje

a) Trastornos del habla:

- Dislalia en caso de problemas para la pronunciación de fonemas.

- Trastorno del ritmo al expresarse.

b) Trastornos del lenguaje:

- Incapacidad para comprender o expresar una idea.

- Tener poco vocabulario para expresarse, que es lo más común, o no comprender el mensaje verbal (afasia).

2. Alteración en los órganos fonoarticulatorios

- Déficit auditivo.

- Déficit mecánico y articulatorio:

- Disglosia (anatómico). Alteración de los órganos fono articulatorios que causa trastorno del habla y lenguaje (labio hendido, fisura palatina, malposición dental, prognatismo, etc.)

- Disartria (motor). Dificultad para la pronunciación de las palabras; de etiología neurológica (parálisis cerebral, distrofias musculares, enfermedad progresiva).

\section{Trastorno piscolinguístico}

- Afasia

- Autismo

- Mutismo selectivo

- Carencia socioafectiva en la infancia. 
El otro aspecto importante para iniciar el abordaje es la integración de la historia clínica orientada hacia los siguientes aspectos:

- Antecedentes heredofamiliares. Investigar a familiares con sordera, trastornos del habla o lenguaje, malformaciones congénitas y alteraciones neurológicas.

- Antecedentes perinatales. Infecciones prenatales considerando TORCH; sustancias teratógenas. Sufrimiento fetal, prematurez, traumatismo obstétrico, sustancias ototóxicas, hiperbilirrubinemia, infecciones del sistema nervioso, hipoxia neonatal. Tamiz auditivo

- Antecedentes patológicos. Infecciones respiratorias altas de repetición (óticas, alergias). Si existe alguna patología sindromática.

- Entorno social, familiar, emocional, etapa escolar, interacción social, juego, dibujo.

- Exploración física con insistencia en dos aspectos importantes: desarrollo intelectual y auditivo.

De acuerdo con los aspectos anteriores, el abordaje debe dirigirse a la búsqueda etiológica de la siguiente manera:

1. Niño con lenguaje ausente, distorsionado o que tarda en hablar:

a) Hipoacusia, déficit intelectual, trastorno de la motricidad bucofaríngea, lesiones cerebrales, espectro autista, hijos de padres sordos.

b) Si se descartan las causas anteriores debe investigarse el nivel de comprensión y expresión para su edad cronológica:

- Trastorno simple del lenguaje. Solo hay alteración fonológica que puede ser por retardo en la madurez del lenguaje, sin alteración en la comprensión.
- Trastorno específico del lenguaje. Alteración en sus fonemas, estructura o contenido. Hay desorganización y distorsión fonológica y comprensión anormal.

2. El niño que deja de hablar: dirigir el interrogatorio hacia los antecedentes neurológicos y al entorno social: afasia, mutismo selectivo, autismo, síndrome de Rett, enfermedad degenerativa.

3. El niño que habla mal: buscar alguna alteración en el ritmo de la palabra: tartamudez, taquilalia, bradilalia, disartria y dislalia.

\section{CONCLUSIONES}

1. El primer contacto con el paciente es el pediatra, quien debe efectuar la detección oportuna y el abordaje integral para una intervención temprana.

2. Para poder detectar oportunamente algún trastorno es indispensable conocer el desarrollo normal del lenguaje.

3. Para lograr la comunicación con el paciente, en las diferentes etapas de su infancia, deben aplicarse las estrategias señaladas.

4. El principal indicador del potencial de inteligencia es el lenguaje.

\section{REFERENCIAS}

1. Pérez PP, Salmerón LT. Desarrollo de la comunicación y del lenguaje: indicadores de preocupación. Rev Pediatr Aten Primaria 2006; 8: 679-93.

2. Barragán PE, Lozanos S. Identificación temprana de trastornos del lenguaje. Rev. Med. Clin. Condes 2011; 22 (2): 227-2323.

3. Johnson CP, Blasco PA. Infant Growth and Development Pediatrics in Review. 1977; 18 (7): 224-42.

4. Ardila A. Orígenes del lenguaje: un análisis desde la perspectiva de las afasias. Rev Neurol. 2006; 43: 690-98.

5. Pérdida de la audición. Clínicas Pediátricas de Norteamérica Vol. 1, McGraw-Hill-Interamericana. 1999. 